\title{
Descriptive, inferential, functional outcome data on 9,025 torture survivors over six years in the United States
}

\author{
Member Centers of the National Consortium of Torture Treatment Programs (NCTTP)
}

\begin{abstract}
Background: The National Consortium of Torture Treatment Programs conducted a large voluntary research project among torture rehabilitation centers in the United States (US). Its goal is to fill the void in the literature on demographic and diagnostic data of torture survivors across a large country.
\end{abstract}

Methods: Twenty-three centers across the US collaborated over six years, utilizing training and making decisions via conference calls and webinars. A data use agreement signed by all the participating centers governed plans and the use of the data.

Findings: This study reports on torture survivors from 125 countries, 109 of which signed the United Nations Convention against Torture (UNCAT). Of the 9,025 torture survivors represented, most came from Africa and Asia and reported an average of 3.5 types of torture. Asylum seekers have different immigration experiences and show significantly higher rates of major depressive disorder (MDD) and posttraumatic stress disorder (PTSD) than refugees. Torture survivors at high risk of PTSD and MDD in this sample reported three or more types of torture, reported rape, and had the immigration status of asylum

Correspondence to: rileyc@ohsu.edu seeker. At one and two years after beginning treatment, both asylum seekers and refugees reported increased rates of employment and improvements in their immigration status. Interpretation: This longitudinal project provides basic data on a large number of torture survivors who accessed services in the US, and provides a foundation for long-term follow up on immigration status, employment status, diagnostic status, medical diagnoses, and eventually, the effectiveness of treatment for torture survivors in the US. This article shares demographic and diagnostic findings useful for informing programmatic and policy decisions. However, these findings on refugees and asylum seekers in the US may not reflect the experience in other receiving countries. Collaboration with other researchers across continents is required to provide a much needed, more complete picture of torture survivors seeking rehabilitation across the world.

Keywords: torture, PTSD, asylum seeker, refugee

\section{Introduction}

According to the United Nations High Commission for Refugees, at the end of 2014, nearly 60 million people were uprooted from their homes by war, conflict, and 
persecution. This is the highest number of displaced persons since World War II. ${ }^{1}$ We expect, based on previous studies, that a significant percentage of these 60 million individuals have been tortured. ${ }^{2}$

Clinical interest and worldwide political attempts to abolish torture as a human rights violation began in a continuous way only after the end of World War II when the Nazi atrocities became apparent. ${ }^{3,4}$ The torture survivor rehabilitation movement developed most notably in countries where final resettlement of refugees took place, and had its beginnings on several continents in the 1970s and early 1980s. At that time, little was known about torture methods or the physical or psychosocial consequences of torture. $^{5}$

Impetus for the movement grew in response to political torture in Chile and through Amnesty International's campaign against torture in Denmark and the inception of the Rehabilitation Council for Torture Victims. It was further advanced by the development of a treatment program in Toronto, and by the work of refugee psychiatric programs in Portland, Oregon, at Harvard in Boston, and in the Twin Cities of Minnesota in the aftermath of the Vietnam War. ${ }^{6-9}$

In the US, programs specifically initiated for the rehabilitation of torture survivors and advocacy began in Los Angeles, Minneapolis, and Chicago in the 1980s, as well as across the rest of the world. ${ }^{10}$ The Torture Victims' Relief Act (TVRA) passed by the US Congress in 1998 mandated funds to establish programs in the US that would provide medical, psychological, social, and legal services for torture survivors. ${ }^{11}$

The Survivors of Torture (SoT) Program was created and implemented through the Office of Refugee Resettlement (ORR), in the Administration of Children \& Families, a federal agency in the US Department of
Health and Human Services. This program greatly increased resources to provide treatment services to those living in the US who had been tortured by foreign governments. Approximately 40 torture treatment programs have received funding from the TVRA in the last 15 years. Thirty torture treatment programs currently receive TVRA funding. In addition, the TVRA provided funding through USAID to assist torture treatment outside the US. Some American torture treatment centers receive funding through the United Nations Voluntary Fund for Victims of Torture.

As programs developed and responded to the needs of torture survivors around the world, more became known about the prevalence of this population and about the repercussions of torture. ${ }^{12,13}$ According to a composite of studies on refugees and torture, it can be conservatively estimated that $10 \%$ to $30 \%$ of refugees in Western settings are survivors of torture. ${ }^{2}$ Wenzel, Kastrup and Eisenman reviewed empirical studies of torture survivors in various publications and reported prevalence rates for torture that vary widely between $3 \%$ and $76 \% .{ }^{14}$

A study in 2008 by Masmas and colleagues found that among asylum seekers from 33 different countries, particularly Afghanistan, Iran, Iraq, Syria, and Chechnya, 45\% had been exposed to torture and $63 \%$ met the criteria for PTSD. ${ }^{15}$ In a meta-analysis of 181 surveys of 81,866 refugees and others exposed to mass conflict and displacement from 40 countries, Steel and colleagues found that torture was the factor most strongly associated with PTSD and was among the strongest predictors of depression. ${ }^{16}$ These studies demonstrate that refugees and asylum seekers are at risk populations for experiencing torture, as well as for meeting criteria for PTSD and MDD.

The US has resettled over three million 
refugees since $1975 .{ }^{17}$ Although asylum seekers who have been tortured have been tracked less carefully than refugees in the US, the data available indicates the numbers of tortured asylum seekers are high. From 1990 to 2013 , more than half a million $(544,740)$ individuals were granted asylum in the US, including 122,812 in the Fiscal Years (FYs) 2009-2013 alone. However, these statistics do not specify which applicants were granted asylum on the basis of torture. ${ }^{18}$ Based on studies presented above, the prevalence of torture survivors in the US is estimated as high.

From additional studies, we know that in Western settings, the prevalence of torture ranges from $7 \%$ to $8 \%$ in general primary care clinics, $6 \%$ to $11 \%$ among foreign born individuals in US primary care, and up to $70 \%$ in refugee psychiatric clinics. ${ }^{10,19,20}$ Even when using a conservative estimate, we are facing an issue of enormous dimensions from both human rights and therapeutic perspectives, an issue that until recently received limited psychiatric, medical, and social services attention.

Although an increasing number of professional papers have been published on torture in scientific journals in the last 15 to 30 years, the data on torture survivors has generally been limited to specific programs in a specific country. ${ }^{10,16}$ Currently, there is minimal data assessing the similarities and differences and the implications for treatment planning among refugees and asylum seekers from diverse backgrounds who have been tortured, fled their homelands, and are now living in a single large country, such as the US. ${ }^{13,21}$

As refugees and asylum seekers are the two main groups of individuals whose torture experiences are reported upon across the world, we need to understand how these two groups both differ and are similar. For example, in response to the same type of torture, do asylum seekers and refugees develop similar rates of MDD or PTSD, and if there are differences in the rates of mental health disorders between asylum seekers and refugees, what factors are associated with these differences? Government leaders and planning groups throughout the world face a variety of opportunities and challenges related to rehabilitating and attending to the needs and rights of refugees and asylum seekers. We still need information about these two groups in various contexts to guide programs and policies.

The literature on torture rehabilitation suggests there are important additional factors for researchers to explore, such as the potentially damaging, long-term impacts of sexual and/or psychological torture, the importance of early or prior trauma on the course of treatment and recovery, and the impact of delays in accessing treatment in the country of resettlement. ${ }^{22,23}$

Jaranson and Quiroga point out that basic research and clinical development among tortured refugees has lagged behind other trauma fields. ${ }^{4}$ Explanations for this slow progress in data collection on torture survivors include the fact that these data are extremely challenging to gather and difficult to systematically study in order to perform outcome studies. Also, resources for research are almost always secondary to those allocated to clinical work.

Torture has been documented since early human history, and yet it is a current public health problem that lacks sufficiently developed evidence-based treatment literature. ${ }^{15}$ In addition to the predictors of psychiatric disorder and the effectiveness of interventions, which have increased in literature in the last decade, professional literature has raised grave concerns about probable relationships between PTSD and 
the later development of serious medical problems, such as cardiovascular disease, hypertension, diabetes, and possibly dementia. ${ }^{24-27}$ Rates of hypertension, hyperlipidemia and diabetes in a household probability sample of Cambodian refugees in the US who survived torture and genocide were significantly higher than in an age and gender adjusted American population sample. ${ }^{28}$

Also of concern are the findings related to traumatic brain injuries as possible repercussions of torture. A survey study with a community sample of 387 tortured former political detainees who had experienced traumatic head injury (THI) and a non-THI ex-detainee comparison group of 82 Vietnamese refugees found a significant independent impact of THI from trauma/ torture on psychiatric morbidity. ${ }^{29}$

This paper is the first in a series of planned studies. The goals of this first report are:

1. To fill a void of data in the literature on torture survivors in one large country and address the lack of basic data on refugees and asylum seekers who have been tortured, have fled their homelands, and now live in the US. We present demographic, type of torture, and psychiatric diagnosis data on 9,025 survivors of torture served by 23 member centers of the US National Consortium of Torture Treatment Programs (NCTTP) from FY2008 through FY2013.

2. To explore similarities and differences between the two main groups of torture survivors served by the NCTTP, refugees and asylum seekers, regarding diagnosis of mental illness, access to treatment in the US, age at first torture, and types of torture experienced; and discuss the implications of these findings related to clinical assessment and treatment planning.
3. To explore the progress made by tortured asylum seekers and refugees on functional outcomes of employment and immigration status.

4. To provide learning points for researchers in other parts of the world on how to plan and build a successful large research project with torture survivors involving many locations.

We will also comment on the usefulness of research on large samples of torture survivors, some of the effective cross-organizational strategies employed to enable our multi-site study, and the need for research into how closely aligned the repercussions of torture are to cardiovascular problems.

\section{Methods}

Overview

This study is a chart review of data collected for treatment purposes or for reporting information to funders by 23 of the 35 member centers of the NCTTP on 9,025 individual torture survivors seen as new intakes in the six years from 30 September 2007 to 29 September 2013. The project required collaboration among 23 torture treatment centers in the US.

The NCTTP, founded in 1998 and incorporated in 2001, is an American based network of programs. Many, but not all, of the NCTTP's 35 members currently receive funding from the ORR. The centers are diverse in their service orientations; most provide some combination of psychiatric, medical, psychotherapeutic, and social services, with less emphasis on legal services, while others include forensic medical and/or psychological services or provide primarily legal assistance. Some centers concentrate primarily on training. Most, but not all NCTTP centers work with both refugees and asylum seekers. Some centers are 
hospital or university based, some are embedded in large social service or human rights organizations, while others are stand-alone non-profit organizations.

Rather than a unified service with one head administrator, the NCTTP is a group of separate centers, governed separately. The centers voluntarily came together for this project because of the enhanced benefits of collaboration, especially on data collection, research, and advocacy planning related to policy. ${ }^{30}$

The protection of client confidentiality was an important concept in the early planning of the NCTTP Research Project. For example, many centers based at universities or hospitals are not allowed to submit data outside of their organizations without the oversight of a university institutional review board (IRB). Other centers believed the data collection could be done without IRB approval. Solving this dilemma took long-term discussion and one year to write a data use agreement together to define how the data collected could and would be used.

The planning and carrying out of the IRB approval process for over 20 centers for the project was beneficial to building rapport, trust, collaborative methods, and viable lines of communication among the 23 torture treatment centers involved and between the center which took responsibility for data collection and those which submitted data.

When submitting data from one center to another, it is not only important to protect the privacy of the torture survivor, it is also vital to be able to answer questions on what the data will be used for, who will receive credit for the data, and who will have a say in how the data will be reported and published.

One of the most important decisions made during the planning of the data use agreement was to make it clear that every publication reporting the data collected would be authored by the centers involved in submitting data. This agreement was signed by the director of each center involved.

The IRB of the Oregon Health \& Sciences University (OHSU) approved the protocol designed by the NCTTP's Research and Data $(\mathrm{R} \& \mathrm{D})$ Committee, with input from one or two staff from each of the 23 member centers. To help ensure the data was of high quality, the study's protocol called for the use of a data codebook with information on how to define and format each variable and provided an Excel file with drop down menus. This file accepted only correctly formatted field responses to ensure the data submitted was correctly formatted.

Over the six years of this project, each researcher submitting data from their torture treatment center was encouraged, supported, and trained through a series of approaches. These included monthly telephone conference calls, special webinar presentations by the NCTTP's R\&D Committee, and by individual telephone and email contacts, as needed, with the chair and co-chair of the NCTTP's R\&D Committee. The OHSU IRB monitored the project to ensure subjects' health information was protected, either through providing monitoring to centers through the project coordinator or by developing cooperative agreements with the participating centres that had internal IRBs.

\section{Design, sampling and eligibility}

This paper describes a retrospective descriptive and inferential study with a non-probability sample of 9,025 torture survivors receiving services at 23 of the NCTTP centers across the US between FY2008 and FY2013. All clients treated by the participating centers were eligible for inclusion in the 
project if their experience met the US definition of torture: "Torture means an act committed by a person acting under the color of law specifically intended to inflict severe physical or mental pain (other than pain or suffering incidental to lawful sanctions) upon another person within his custody or lawful control." 11 This definition was used by necessity because programs that receive TVRA funding are required to use this definition to determine eligibility for services. We used this definition of torture to ensure consistent eligibility criteria across all participating centers.

\section{Measures}

For the first year, the project collected 10 basic demographic variables on the survivors at intake, such as gender, age, country of origin and immigration status. In the second year, current immigration status was added.

Beginning in FY2010, specific information on 11 additional variables not already collected by the project was requested of grantees by the ORR, such as types of torture reported, age at first torture, and time in the US prior to admission to treatment. Definitions and formatting requirements for variables required by the ORR were used in the NCTTP project to promote consistency across data collection sites. For FYs 2011 to 2013, four to five data variables were added each year. These new data variables, which included mental illness diagnoses, years of education in country of origin, and social networks, were determined by consensus by the members of the NCTTP's R\&D Committee. Follow up information was collected on employment and immigration status by some of the NCTTP centers.

Statistical analyses

Descriptive analyses were conducted using
IBM SPSS Statistic 22. Pearson Chi Square tests of independence examined the relationship between gender and types of torture. Transgender survivors were omitted from these analyses due to their small number. To obtain a clearer picture of the impact of immigration status on diagnoses, we conducted an analysis on the sub-sample of survivors who had a legal status of either refugee or asylum seeker. We omitted the $22 \%$ of the dataset with other immigration status, (i.e., asylee, lawful permanent resident, US citizen, and other legal status) from this analytic sample.

This smaller dataset, $\mathrm{N}=6,533$, consisted of $65 \%$ asylum seekers and $35 \%$ refugees and represents $77.6 \%$ of the whole dataset. Using Pearson Chi Square tests of independence, with Yates Continuity Correction, we examined the relationship between various demographic characteristics of survivors (i.e., age group at intake, gender, religion, region of origin, region of the US where they received treatment) and immigration status (refugee vs. asylum seeker). A one-way ANOVA was conducted to examine whether years of education in country of origin or age at intake differed based on immigration status.

We conducted Chi-Square tests of independence to examine the association between immigration status and several other variables we expected may have an important impact on the diagnosis. These variables included time spent in the US prior to accessing treatment, types of torture reported and age at first torture.

Determining the outcome of clients in torture treatment programs is one of the long-term goals of the NCTTP Research Project. As a first step in exploring client changes over time, we analyzed two objective measures, change in immigration status (collected since FY2009) and employment 
status (collected since FY2011) from intake to follow up at one and two years. Examining these changes in immigration and employment at follow up at one and two years, we defined improvement in status as "any change in status that moved the survivor toward the ideal immigration goal of becoming a US citizen" and as "any change in status that moved the survivor toward the ideal goal of employment", whether full or part-time.

The steps asylum seekers must go through to become a US citizen include:

1. Being granted asylum.

2. Becoming a lawful permanent resident.

3. Becoming a US citizen. Refugees are required to go through steps two and three.

For asylum seekers to gain employment, they generally need to:

1. Obtain work authorization.

2. Seek employment.

3. Gain employment. Since refugees already have a legal status in the US they are not required to obtain work authorization.

Further details on the development of the NCTTP's Research Project are available by contacting the authors and accessing the NCTTP website. ${ }^{30}$

\section{Results}

The 9,025 individuals came from 125 different countries. One of two countries, Ethiopia and Iraq, contributed the most torture survivors every year of the six-year project. Fourteen of the 125 countries (see Table 1) account for $64.2 \%(5,792)$ of the torture survivors. Eighty-seven percent (109) of the 125 countries are signatories to the UNCAT. Of the 14 countries contributing the most torture survivors to our study, 13 are signatories (Ethiopia, Iraq, Somalia, Bosnia, Cameroon, Uganda, Democratic Republic of the Congo, Eritrea, Cambodia, Sudan, China, Afghanistan, and Guatemala).

The torture survivors in this study are from all five major regions of the world, with over half (51\%) coming from Africa, $31 \%$ from Asia, $6 \%$ from the Americas, 9\% from Europe, and 2\% from the Pacific Islands.

Males slightly outnumbered females, $53 \%$ to $46.4 \%$, with $0.6 \%$ of the survivors identifying as transgender. The age range at intake of survivors was from toddlers to over 80 , with an average age of 40.2 years. Most survivors were between 25 and 44 years old at intake, $7 \%$ were children under 14 years, and $13.6 \%$ were over 65 . Demographic data is shown in Table 2. In terms of religious affiliation, $84 \%$ were either Christian or Muslim (46.3\% and $37.4 \%$ respectively) (see Table 2). Three religions were represented at less than $10 \%$, i.e., Buddhist, $7.5 \%$; Hindu, $2 \%$; and Agnostic, 2\%.

Examining immigration status at the time of intake, asylum seekers were the largest group $(50.3 \%)$ in our dataset, followed by refugees $(27.5 \%)$, lawful permanent residents $(5.6 \%)$, asylees $(5.3 \%$; i.e., those who have been granted asylum in the US), naturalized US citizens (3.3\%), and other (8.2\%; which includes individuals in the US on legal visas for work, study, and other categories of stay).

\section{Demographic and social differences between} asylum seekers and refugees

Asylum seekers, when compared to refugees, were more likely to be male $(56.9 \%$ of asylum seekers versus $49.1 \%$ of refugees), younger (averaging 37.1 years of age at intake for asylum seekers versus 43.4 years of age for refugees), single ( $40 \%$ of asylum seekers versus $23 \%$ of refugees), have had more education in their home countries 
Table 1: Countries listed in order of the number of torture survivors, from a given country, seeking treatment in the NCTTP centers during US Federal FY2008 to 2013. Total N = 9,025 from 125 countries. The names of 65 countries are listed. An asterisk by the name indicates the country is a signatory to the UNCAT. One hundred and nine countries in this dataset have signed.

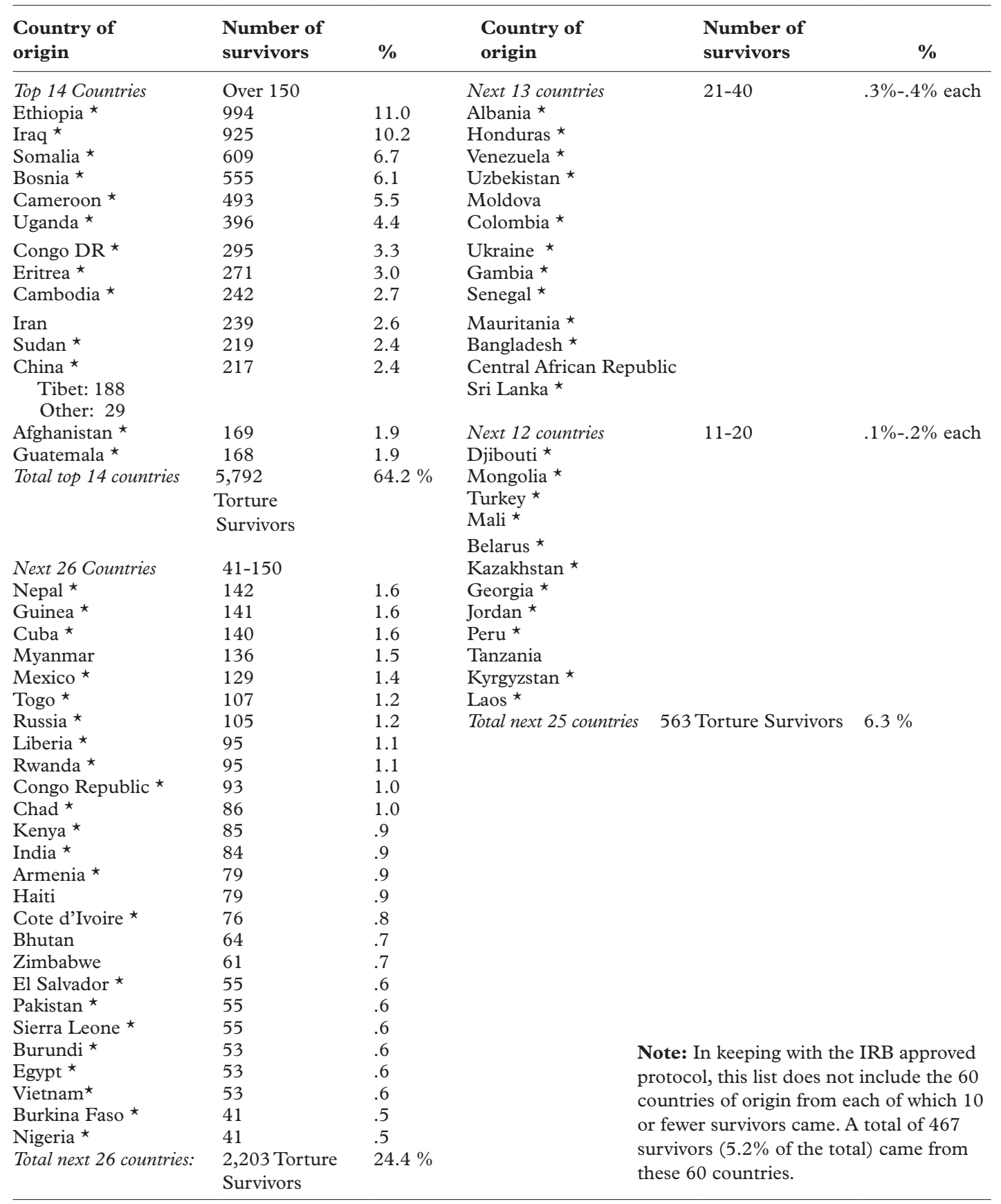


Table 2: Demographic and social variables for Full Data Set ${ }^{a}$

\begin{tabular}{lll}
\hline Variables & Total N & Percent or mean (SD) (range) \\
\hline Gender & 9,025 & \\
Male & & $53 \%$ \\
Female & $46.4 \%$ & $0.6 \%$ \\
Other & 975 & \\
Marital Status ${ }^{\text {b }}$ & & $53 \%$ \\
Married & & $31 \%$ \\
Single & & $9 \%$ \\
Divorced/Separate & & $7 \%$ \\
Widowed & \multirow{2}{*}{8,707} & $40.18(13.7)$ (toddler to over 80$)$ \\
Age at Intake, mean (SD) & & $0.3 \%$ \\
Under 5 years & & $4.9 \%$ \\
5 to 13 years & & $1.8 \%$ \\
14 to 17 years & & $10.6 \%$ \\
18 to 24 years & & $43 \%$ \\
25 to 44 years & & $25.7 \%$ \\
45 to 64 & & $13.6 \%$ \\
65 and over & & \\
\end{tabular}

Regions of origin

8,850

Africa

$51 \%$

Asia

Americas

$31 \%$

Europe

$6 \%$

Pacific Islanders

$9 \%$

$2 \%$

Years of education in country of origin ${ }^{c}$ mean (SD) (range)

600

$11.8(4.9)(0-22)$

Immigration status at Intake

8,391

Asylum seeker

$50.6 \%$

Refugee

$27.3 \%$

Lawful Permanent Resident (LPR)

$5.5 \%$

Asylee

$5.3 \%$

US citizen

$3.3 \%$

Other

$8 \%$

Employment status at intake ${ }^{\mathrm{d}}$

4,611

No work authorization

$39.5 \%$

Unemployed - not seeking

$14.0 \%$

Unemployed - seeking

$11.4 \%$

Employed

$16.4 \%$

Unable to work due to physical/mental condition 


\begin{tabular}{lll}
\hline Variables & Total N & Percent or mean (SD)(range) \\
\hline Student & $9.7 \%$ \\
Primary caregiver not employed outside the house & $5.8 \%$ \\
Other & $2.5 \%$ \\
Religion & \\
Buddhist $^{\text {Hindu }}$ & \\
Hindian & $7.815 \%$ \\
Christian & $2.1 \%$ \\
Muslim & $48.0 \%$ \\
Agnostic & $38.5 \%$ \\
Other & $2 \%$ \\
& $1.9 \%$ \\
Area of US where received treatment & \\
East & \\
Mid-country & 9,025 & \\
West & $41.4 \%$ \\
\hline
\end{tabular}

${ }^{\mathrm{a}}$ The total number of survivors in the data set is 9,025 , but the $\mathrm{N}$ for individual variables ranges from 975 to 9,025 .

${ }^{\mathrm{b}}$ New variable in FY2013 / c New variable in FY2012 / d New variable in FY2010

(13.8 years for asylum seekers versus 9.75 years for refugees) (see Table 3).

In addition, asylum seekers were more likely to be from African countries (68\% of asylum seekers) and to identify as a member of the Christian religion $(64.5 \%$ of asylum seekers), compared to refugees who were from Asian countries (50\% of refugees) and more likely to identify as a member of the Muslim religion (66.1\% of refugees) (see Table 3).

\section{Types of torture}

We collected data on sixteen different types of torture. Looking at the whole data set, beatings and threats were the types of torture most highly reported, by $67.3 \%$ and $67.2 \%$ of torture survivors, respectively. A large majority, $81 \%$, reported more than one type of torture, and $29 \%$ reported experiencing five or more types. On average, clients experienced 3.5 types of torture. While the number of types of torture experienced by males and females was similar, the types of torture they experienced varied to some degree, as outlined in Table 4 . The greatest gender difference was experienced in the reporting of rape $31.1 \%$ of females versus $8.1 \%$ of males). Refugees and asylum seekers showed the greatest differences in the reporting of three types of torture, beatings ( $80.4 \%$ of asylum seekers versus $56.8 \%$ of refugees), witnessing (23.8\% of asylum seekers versus $52.9 \%$ of refugees), and rape (26.2\% of asylum seekers versus $8.7 \%$ of refugees).

The most common age range for "age at first torture" was $25-44$, reported by $45 \%$ of the torture survivors.

However, a similar number, $46.1 \%$ reported that their first experience of torture occurred before the age of 25 , with $23 \%$ 
Table 3: Demographic and social differences between asylum seekers and refugees treated in NCTTP centers from US Federal FY 2008 through 2013

\begin{tabular}{|c|c|}
\hline Variables & $\begin{array}{l}\text { Total }^{\mathrm{d}} \text { asylum seekers }+ \text { refugees } \\
\text { N / \% }\end{array}$ \\
\hline Gender & Total $\mathrm{N}=6,430^{\mathrm{d}}$ \\
\hline Male & $3,478 / 54.1 \%$ \\
\hline Female & $2,903 / 45.1 \%$ \\
\hline Other & $49 / .8 \%$ \\
\hline Marital status ${ }^{\mathrm{a}}$ & Total $\mathrm{N}=833^{\mathrm{d}}$ \\
\hline Married & $466 / 56 \%$ \\
\hline Single & $275 / 33 \%$ \\
\hline Divorced/Separated & $50 / 6 \%$ \\
\hline Widowed & $42 / 5 \%$ \\
\hline & Total $\mathrm{N}=6,335^{\mathrm{d}}$ \\
\hline Age at intake, mean (SD), y & $39.6(13.1)$ \\
\hline Five regions of the world & Total $\mathrm{N}=6,331^{\mathrm{d}}$ \\
\hline Africa & $52.8 \%$ \\
\hline Asia & $29.9 \%$ \\
\hline Americas & $4.9 \%$ \\
\hline Europe & $9.6 \%$ \\
\hline Pacific Islanders & $2.8 \%$ \\
\hline $\begin{array}{l}\text { Top five countries of origin for asylum } \\
\text { seekers }+ \text { refugees }\end{array}$ & $\begin{array}{l}\text { Ethiopia } 812 / 12 \% \\
\text { Iraq } 749 / 11.5 \% \\
\text { Somalia } 487 / 7.5 \% \\
\text { Bosnia } 445 / 6.8 \% \\
\text { Cameroon } 362 / 5.5 \% \\
\text { Total } \mathrm{N}=2855 / 44.4 \% \text { of asylum seekers }+ \text { refugees }\end{array}$ \\
\hline $\begin{array}{l}\text { Years of education in country of origin, }{ }^{\mathrm{b}} \\
\text { mean (SD) (Range) }\end{array}$ & $\begin{array}{l}\text { Total } \mathrm{N}=423^{\mathrm{d}} \\
12.2(5.1)(0-22)\end{array}$ \\
\hline Religion $^{\mathrm{c}}$ & Total $\mathrm{N}=3,628 \mathrm{~d}$ \\
\hline Buddhist & $176 / 4.9 \%$ \\
\hline Hindu & $85 / 2.3 \%$ \\
\hline Christian & $1,758 / 48.5 \%$ \\
\hline Muslim & $1,454 / 40.1 \%$ \\
\hline Agnostic & $76 / 2.1 \%$ \\
\hline Other & $79 / 2.2 \%$ \\
\hline Area of US where receiving treatment & Total $\mathrm{N}=6,533^{\mathrm{d}}$ \\
\hline East & $2,576 / 39.4 \%$ \\
\hline Mid-country & $2,158 / 33 \%$ \\
\hline West & $1,799 / 27.5 \%$ \\
\hline
\end{tabular}

a New variable in FY2013 / b New variable in FY2012 / c New variable in FY2010 /

d Total for immigration categories of asylum seekers + refugees ${ }^{\mathrm{e}} \mathrm{p}$ values were for Pearson Chi Square test

${ }^{\mathrm{f}} \mathrm{p}$ values were for ANOVA test 


\begin{tabular}{|c|c|c|}
\hline $\begin{array}{l}\text { Asylum seekers } \\
\text { N / \% }\end{array}$ & $\begin{array}{l}\text { Refugees } \\
\text { N / \% }\end{array}$ & P-value \\
\hline $\mathrm{N}=4,151$ & $\mathrm{~N}=2,279$ & $\mathrm{p}<.000^{\mathrm{e}}$ \\
\hline $2,360 / 56.9 \%$ & $1,118 / 49.1 \%$ & \\
\hline $1,743 / 42.0 \%$ & $1,160 / 51.2 \%$ & \\
\hline $49 / 1.2 \%$ & $1 / .0 \%$ & \\
\hline $\mathrm{N}=502$ & $\mathrm{~N}=331$ & \\
\hline $256 / 51 \%$ & $208 / 63 \%$ & \\
\hline $201 / 40 \%$ & $76 / 23 \%$ & \\
\hline $35 / 7 \%$ & $17 / 5 \%$ & \\
\hline $10 / 2 \%$ & $30 / 9 \%$ & \\
\hline $\mathrm{N}=4,165$ & $\mathrm{~N}=2,170$ & $\mathrm{p}<.000^{\mathrm{f}}$ \\
\hline $37.3(11.1)$ & $43.4(15.4)$ & \\
\hline $\mathrm{N}=4,076$ & $\mathrm{~N}=2,255$ & $\mathrm{p}<.000^{\mathrm{e}}$ \\
\hline $68 \%$ & $24 \%$ & \\
\hline $19 \%$ & $50 \%$ & \\
\hline $7 \%$ & $1 \%$ & \\
\hline $4 \%$ & $20 \%$ & \\
\hline $2 \%$ & $5 \%$ & \\
\hline Ethiopia -779 & Iraq -698 & \\
\hline Cameroon - 353 & Bosnia -441 & \\
\hline Somalia -311 & Somalia -176 & \\
\hline Uganda -270 & Cuba -103 & \\
\hline Eritrea -178 & Myanmar - 96 & \\
\hline $\mathrm{N}=1850 / 44.7 \%$ of asylum seekers & $\mathrm{N}=1500 / 66 \%$ of refugees & \\
\hline $\mathrm{N}=253$ & $\mathrm{~N}=171$ & $\mathrm{p}<.000^{\mathrm{f}}$ \\
\hline $13.8(4.2)(0-22)$ & $9.75(5.1)(0-18)$ & \\
\hline $\mathrm{N}=2,093$ & $\mathrm{~N}=1,433$ & $\mathrm{p}<.000^{\mathrm{e}}$ \\
\hline $84 / 4 \%$ & $87 / 6.1 \%$ & \\
\hline $71 / 3.4 \%$ & $12 / .8 \%$ & \\
\hline $1,349 / 64.5 \%$ & $348 / 24.3 \%$ & \\
\hline $473 / 22.6 \%$ & $947 / 66.1 \%$ & \\
\hline $56 / 2.7 \%$ & $20 / 1.4 \%$ & \\
\hline $60 / 2.9 \%$ & $19 / 1.3 \%$ & \\
\hline $\mathrm{N}=4246$ & $\mathrm{~N}=2287$ & $\mathrm{P}<.000^{\mathrm{e}}$ \\
\hline $2,152 / 83.5 \%$ & $424 / 16.5 \%$ & \\
\hline $749 / 34.7 \%$ & $1,409 / 66.3 \%$ & \\
\hline $1,345 / 74.8 \%$ & $454 / 25.2 \%$ & \\
\hline
\end{tabular}


Table 4: Percentage of types of torture experienced by torture survivors treated in NCTTP centers from US Federal Fiscal Years 2010 - 2013, by gender

\begin{tabular}{|c|c|c|c|c|}
\hline $\begin{array}{l}\text { Types of torture } \\
\text { experienced }\end{array}$ & $\begin{array}{l}\text { Percent of } \\
\text { total }^{\text {a }} \\
N=3,096\end{array}$ & $\begin{array}{l}\text { Percent of } \\
\text { males }^{\mathrm{a}} \\
\mathbf{N}=1,744\end{array}$ & $\begin{array}{l}\text { Percent of } \\
\text { females }^{\mathrm{a}} \\
\mathrm{N}=1,352\end{array}$ & P-valueb, ${ }^{\text {b, c }}$ \\
\hline Beatings & 67.3 & 72.3 & 60.9 & $\mathrm{P}<.000$ \\
\hline Threats & 67.2 & 66.8 & 67.6 & NS \\
\hline Witnessing & 39.2 & 38.5 & 40 & NS \\
\hline Deprivation & 35.4 & 39.7 & 29.9 & $\mathrm{P}<.000$ \\
\hline Severe humiliation & 27.3 & 26.6 & 28.1 & NS \\
\hline Sensory stress & 26.1 & 29.6 & 21.6 & $\mathrm{P}<.000$ \\
\hline Wounding & 25.9 & 31.7 & 18.4 & $\mathrm{P}<.000$ \\
\hline Rape & 18.6 & 8.1 & 32.1 & $\mathrm{P}<.000$ \\
\hline Kidnapping & 14.7 & 16.2 & 12.9 & $\mathrm{P}<.01$ \\
\hline Forced postures & 13.0 & 16.3 & 8.9 & $\mathrm{P}<.000$ \\
\hline Asphyxiation & 5.7 & 4.2 & 7.7 & $\mathrm{P}<.000$ \\
\hline Burning & 4.9 & 5.7 & 4.1 & NS \\
\hline Pharmacological & 1.2 & 1.5 & .8 & NS \\
\hline Dental & .6 & .6 & .6 & NS \\
\hline
\end{tabular}

${ }^{a}$ For the sub-set from whom we have data on types of torture

${ }^{\mathrm{b}} \mathrm{p}$ values are for the gender difference

c All p values were for Pearson Chi Square test

Note: The variable, type of torture, was first collected in 2010. Percentages indicate those who reported the type of torture

reporting being tortured for the first time as children, i.e., before the age of 18 . Only $8.9 \%$ reported being tortured for the first time at over the age of 45 .

\section{Psychiatric diagnoses and associated characteristics}

High rates of PTSD and MDD were found in torture survivors in our study (see Table 5). Sixty-nine percent were diagnosed with PTSD, while $52.4 \%$ had a diagnosis of MDD. Thirty-five percent were diagnosed with PTSD co-morbid with MDD. The source of the intake diagnosis is known for $87 \%$ of the individuals for whom we have diagnostic data. In over $99 \%$ of these, a psychiatrist or another licensed professional made the diagnosis based on a clinical interview. Another mental health clinic or a diagnostic screening instrument, in house, provided the remaining $<1 \%$ of diagnoses.

The immigration status of asylum seeker was associated with statistically higher rates of any PTSD and any MDD diagnosis at intake compared to a status of refugee, $73 \%$ vs. $64 \%$ for PTSD ( $<$ <.000), and $53 \%$ vs. $36 \%$ for MDD $(\mathrm{p}<.000)$ (see Table 5$)$.

Refugees had statistically higher rates of any MDD at intake if they accessed treatment more than one year after arriving in the US versus accessing treatment at one year or less $(48.8 \%$ vs. $30.9 \%$; p<.01). There were no significant differences for asylum seekers 
Table 5: Psychiatric diagnoses made by licensed clinicians for torture survivors treated in NCTTP centers broken down by asylum seeker and refugee status (US Federal FY 2011 through 2013)

\begin{tabular}{|c|c|c|c|}
\hline Psychiatric diagnoses for torture survivors ${ }^{b}$ & $\begin{array}{l}\text { Total } \\
N=1,360^{\mathrm{a}, \mathrm{b}} \\
\mathrm{N} / \%\end{array}$ & $\begin{array}{l}\text { Asylum Seekers } \\
\mathbf{N}=\mathbf{6 8 6}^{\mathrm{b}} \\
\mathrm{N} / \%\end{array}$ & $\begin{array}{l}\text { Refugees } \\
\mathbf{N}=285^{\mathrm{b}} \\
\mathbf{N} / \%\end{array}$ \\
\hline Any Posttraumatic Stress Disorder (PTSD) $)^{\mathrm{c}}, \star{ }^{\star}$ & $938 / 69$ & $502 / 73$ & $181 / 64$ \\
\hline PTSD only & $409 / 30.1$ & $245 / 35.7$ & $101 / 35.4$ \\
\hline Any Major Depressive Disorder (MDD) ${ }^{\mathrm{c}},{ }^{\star}$ & $713 / 52.4$ & $363 / 53$ & $102 / 36$ \\
\hline MDD only & $185 / 13.6$ & $103 / 15$ & $28 / 9.8$ \\
\hline \multicolumn{4}{|l|}{ Co-occurring conditions } \\
\hline MDD + PTSD & $437 / 32.1$ & $215 / 31.3$ & $63 / 22.1$ \\
\hline MDD + other ${ }^{\mathrm{d}}$ & $47 / 3.5$ & $19 / 2.8$ & $7 / 2.5$ \\
\hline PTSD + other ${ }^{d}$ & $48 / 3.5$ & $16 / 2.3$ & $13 / 4.6$ \\
\hline $\mathrm{MDD}+\mathrm{PTSD}+$ other $^{\mathrm{d}}$ & $44 / 3.2$ & $26 / 3.8$ & $4 / 1.4$ \\
\hline Other diagnoses $^{\mathrm{d}}$ & $190 / 14$ & $62 / 9$ & $69 / 24.2$ \\
\hline
\end{tabular}

a Psychiatric diagnoses were collected by the project for the first time in FY2011

$\mathrm{b}$ This data were not available for every survivor in our study

${ }^{\mathrm{c}}$ Either alone or in combination with another diagnosis

d Other diagnoses include: Adjustment disorder, generalized anxiety disorder, anxiety disorder NOS ${ }^{\star} \mathrm{p}<.000$. Pearson Chi Square Test (with Yates Continuity Correction) of the relationship between immigration status (asylum seeker vs. refugee) and diagnosis

Note: The effect sizes are small (.20)

on the rate of MDD or for the two groups on diagnoses of PTSD related to length of time in the US prior to treatment. Both groups showed higher rates of PTSD than MDD. Both genders had significantly higher rates of MDD when treatment was accessed more than one year after arriving in the US ( $64.3 \%$ vs. $47.9 \%$ for females, $\mathrm{p}<.01$, and $54.2 \%$ vs. $42.9 \%$ for males, $\mathrm{p}<.01)$. No significant association was found between length of time in the US and PTSD for either gender.

\section{Number of types of torture and} psychiatric diagnosis

The diagnostic rates of MDD and PTSD were related to the number of types of torture reported, although the effect sizes were small. The rates of PTSD were significantly related to number of types of torture reported, regardless of immigration status: For one or two types of torture reported, we found rates of PTSD at $67.8 \%$, for three or four types, PTSD at $73 \%$, and over four types, PTSD at $80.9 \%(\mathrm{~N}=866 ; \mathrm{p}<.01)$. This significant pattern of higher rates of PTSD found in those with a higher number of types of torture experienced was also found for asylum seekers $(69.4 \%$ for one to two types, $75.3 \%$ for three to four types, and $83.2 \%$ for over four types of torture; $\mathrm{p}<.01$ ) but not for refugees, of whom $63 \%$ to $65 \%$ were diagnosed with PTSD regardless of number of types of torture experienced. 
Regarding depression, those who reported three or more types of torture had significantly higher rates of diagnosed MDD compared to those who reported one or two types of torture (45\% vs. $52.6 \%$ with MDD) regardless of immigration status $(\mathrm{N}=866$; $\mathrm{p}<.05)$.

There were no significant differences in rates of MDD found to be associated with the number of types of torture when examined separately for asylum seekers and refugees.

Rape, gender, demographic characteristics and mental health diagnosis

Almost one-fifth (18.6\%) of the survivors on whom we have information on type of torture reported they were raped. Among the torture survivors reporting rape, we found a high representation of asylum seekers (83\%), females (74\%), Christians (73\%), Africans $(65 \%)$, and those with at least five years of education (68\%). Looking at the top 10 countries of origin in our dataset that contributed the most survivors, we found that rape was most highly reported in two countries in Africa: Uganda and the Democratic Republic of Congo. Fifty-eight percent (225) of the torture survivors from Uganda reported experiencing rape while $40 \%$ (170) of the survivors from the Democratic Republic of Congo reported that they had experienced rape. Of the torture survivors reporting rape, $17 \%$ were Asian.

In addition, torture survivors reporting rape included high numbers of survivors who reported more than two (over 80\%) and more than four (44\%) types of torture, and large numbers of survivors who reported they had been beaten ( $82 \%)$. Nearly two-thirds $(62.4 \%)$ of those reporting rape $(\mathrm{N}=178)$ were diagnosed with MDD, more than three-quarters (79.2\%) with PTSD, and $46 \%$ with both MDD and PTSD. Of these, females who reported rape were significantly more likely to be diagnosed than not to be diagnosed with MDD at intake (64\% vs. $36 \%$; $<.05)$. No significant gender associations were found for PTSD diagnosis among those who reported being raped.

The effect size is small for many of the above analysis. However, given the large national sample in this study, this information is useful for informing programmatic and policy decisions.

Age at first torture (age when first subjected to torture)

Prior trauma, especially childhood trauma, has been found to be a predictor of the development of PTSD after more recent trauma. ${ }^{23}$ To look at this question, we explored whether or not age at first torture would have an impact on diagnosis. In this study, we found no difference in rates of diagnosis of MDD or PTSD in either refugees or asylum seekers related to age at first torture.

\section{Exploring functional outcomes Improvements in} immigration status over time

More than one-third (36\%) of the 1,440 individual torture survivors with follow up data on changes in immigration status one year after intake showed improved immigration status (see Table 6), defined as any change in immigration status that moved the survivor toward US citizenship. For those 488 survivors with two year follow up data, $49 \%$ reported an improved immigration status, i.e., movement toward US citizenship.

We also examined change in immigration status separately for asylum seekers and refugees (see Table 6). Among the asylum seekers for whom we had follow up data $(\mathrm{N}=776), 30.3 \%$ showed progress after one year. Two hundred and nineteen were granted asylum, and 16 additional individu- 
Table 6: Changes in NCTTP immigration status from intake to one-year and two-year follow up

\begin{tabular}{lll}
\hline Changes in NCTTP immigration status & $\begin{array}{l}\text { One-year follow up } \\
\text { N (\%) }\end{array}$ & $\begin{array}{l}\text { Two-year follow up } \\
\text { N (\%) }\end{array}$ \\
\hline $\begin{array}{l}\text { All immigration categories } \\
\text { Movement toward US citizenship }\end{array}$ & $\mathrm{N}=1440$ & $\mathrm{~N}=488$ \\
& $513(36 \%)$ & $239(49 \%)$ \\
Individual survivors by immigration category & $\mathrm{N}=513$ & $\mathrm{~N}=239$ \\
By immigration category & $\begin{array}{l}\text { AS to Asylee: } 199 \\
\text { Asylee to REF: } 2\end{array}$ & $\begin{array}{l}\text { AS to Asylee: } 105 \\
\text { Asylee to REF: } 0\end{array}$ \\
& Asylee to LPPR: 24 & Asylee to LPR: 17 \\
& REF to LPR: 144 & REF to LPR: 71 \\
& LPR to US citizen: 37 & LPR to US citizen: 23 \\
Asylum seekers & Other to legal status: 107 & Other to legal status: 23 \\
Movement toward US citizenship & $\mathrm{N}=776$ & $\mathrm{~N}=290$ \\
Refugees & $235(30.3 \%)$ & $126(43.4 \%)$ \\
Movement toward US citizenship & $\mathrm{N}=378$ & $\mathrm{~N}=116$ \\
\hline
\end{tabular}

Legend: AS (asylum seeker) / Asylee / REF (refugee) / LPR (legal permanent resident) / US citizen

${ }^{\text {a }}$ For those survivors on whom we have immigration status data at Year 1 and Year 2 follow up

als became lawful permanent residents. At follow up at two years, data was obtained from a smaller number $(\mathrm{N}=290)$, of whom $43 \%$ reported an improvement in their immigration status.

For refugees at one-year follow up $(\mathrm{N}=$ 378 ), $43 \%$ had made positive changes to immigration status: 144 had become lawful permanent residents and 18 other individuals had become US citizens. We obtained two-year follow up data for 116 of the refugees. Seventy-two percent of these made movements toward US citizenship.

Improvements in employment status over time We examined changes in survivors' employment status one and two years after intake (see Table 7). Similar to our examination of immigration status, we measured progress toward the goal of employment (either full- or part-time).
At one year after intake, $33.1 \%$ of the 504 survivors for whom we had follow up data were either employed or closer to obtaining employment than at intake. At two years after intake, our follow up data on 667 survivors receiving services showed that $41.6 \%$ had progressed toward employment or were employed. We also compared employment status changes specifically for asylum seekers and refugees. Table 7 outlines employment from intake to follow up for the follow up dataset and compares employment outcomes for asylum seekers and refugees.

For asylum seekers, the percent employed from intake to one year follow up increased from $10.5 \%$ to $32 \%$; for refugees, from $21.6 \%$ to $28 \%$, and, for the full dataset, including asylees, legal permanent residents, and US citizens, from $11.4 \%$ to $29.2 \%$.

From intake to one year follow up all 
Table 7: Change in employment status from intake to follow up by immigration status

\begin{tabular}{|c|c|c|}
\hline & Employment status & $\begin{array}{l}\text { Full data set } \\
\text { N } / \%\end{array}$ \\
\hline \multirow[t]{9}{*}{ Intake } & Employment status at intake ${ }^{a}$ & Total $\mathrm{N}=4611$ \\
\hline & No work authorization & $1819 / 39.5 \%$ \\
\hline & Unemployed - not seeking & $648 / 14 \%$ \\
\hline & Unemployed - seeking & $528 / 11.5 \%$ \\
\hline & Employed $^{\mathrm{b}}$ & $757 / 16.4 \%$ \\
\hline & Unable to work ${ }^{\mathrm{c}}$ & $29 / .6 \%$ \\
\hline & Student & 449 / 9.7\% \\
\hline & Primary caregiver & $268 / 5.8 \%$ \\
\hline & Other & $113 / 2.5 \%$ \\
\hline \multirow[t]{11}{*}{1 Year follow up } & & $\mathrm{N}=610$ \\
\hline & Employment status at follow up ${ }^{a}$ & Survivors 1 YR \\
\hline & & Follow up data Employment \\
\hline & No work authorization & $172 / 28.2 \%$ \\
\hline & Unemployed - Not Seeking & $51 / 8.4 \%$ \\
\hline & Unemployed - Seeking & $99 / 16.2 \%$ \\
\hline & Employed b & $178 / 29.2 \%$ \\
\hline & Unable to work c & $42 / 6.9 \%$ \\
\hline & Student & $20 / 3.3 \%$ \\
\hline & Primary caregiver $\mathrm{d}$ & $7 / 1.1 \%$ \\
\hline & Other & $41 / 6.7 \%$ \\
\hline \multirow[t]{4}{*}{1 Year } & & $\mathrm{N}=504$ \\
\hline & Movement $>$ Employment ${ }^{\mathrm{e}}$ & $167 / 33.1 \%$ \\
\hline & Pending movement & $227 / 45 \%$ \\
\hline & Other & $110 / 21.8 \%$ \\
\hline \multirow[t]{4}{*}{2 Year } & & $\mathrm{N}=667$ \\
\hline & Movement $>$ Employment $\mathrm{t}^{\mathrm{e}}$ & $276 / 41.4 \%$ \\
\hline & Pending movement & $308 / 46.2 \%$ \\
\hline & Other & $83 / 12.4 \%$ \\
\hline
\end{tabular}

\footnotetext{
${ }^{\text {a }}$ Employment status was measured at time of intake into torture treatment program and at follow up one and two year(s) later

${ }^{\mathrm{b}}$ Either full- or part-time employment

c Unable to work due to current physical or mental disability or condition

d Primary caregiver not employed outside the house

e Movement $>$ toward employment
} 


\begin{tabular}{|c|c|c|}
\hline $\begin{array}{l}\text { Asylum seekers }+ \text { refugees } \\
\mathrm{N} / \%\end{array}$ & $\begin{array}{l}\text { Asylum seekers (AS) } \\
\text { N / \% }\end{array}$ & $\begin{array}{l}\text { Refugees } \\
\text { (REF) } \\
\text { N / \% }\end{array}$ \\
\hline Total $\mathrm{N}=3560$ & $\mathrm{~N}=2049$ & $\mathrm{~N}=1511$ \\
\hline $1555 / 43.6 \%$ & $1533 / 74.8 \%$ & $22 / 1.5 \%$ \\
\hline $464 / 13 \%$ & $73 / 3.6 \%$ & $391 / 25.9 \%$ \\
\hline $384 / 10.8 \%$ & $62 / 3.0 \%$ & $322 / 21.3 \%$ \\
\hline $543 / 15.3 \%$ & $216 / 10.5 \%$ & $327 / 21.6 \%$ \\
\hline $314 / 8.8 \%$ & $32 / 1.6 \%$ & $282 / 18.7 \%$ \\
\hline $202 / 5.7 \%$ & $60 / 2.9 \%$ & $142 / 9.4 \%$ \\
\hline $\begin{array}{l}21 / .6 \% \\
77 / 2.2 \%\end{array}$ & $\begin{array}{l}5 / .3 \% \\
68 / 3.3 \%\end{array}$ & $\begin{array}{l}16 / 1.0 \% \\
9 / .6 \%\end{array}$ \\
\hline $\mathrm{N}=454$ & $\mathrm{~N}=344$ & $\mathrm{~N}=110$ \\
\hline AS + REF 1 YR & AS 1 YR & REF 1 YR \\
\hline Follow up data Employment & Follow up data Employment & Follow up data Employment \\
\hline $136 / 30 \%$ & $136 / 39.5 \%$ & $0 / 0 \%$ \\
\hline $29 / 6.4 \%$ & $13 / 3.8 \%$ & $16 / 15.0 \%$ \\
\hline $82 / 18.1 \%$ & $61 / 17.7 \%$ & $21 / 17.8 \%$ \\
\hline $140 / 30.8 \%$ & $110 / 32.0 \%$ & $30 / 28.0 \%$ \\
\hline $29 / 6.4 \%$ & $1 / .3 \%$ & $28 / 25.2 \%$ \\
\hline $13 / 2.9 \%$ & $5 / 1.5 \%$ & $8 / 7.5 \%$ \\
\hline $5 / 1.0 \%$ & $1 / .3 \%$ & $4 / 3.7 \%$ \\
\hline $20 / 4.4 \%$ & $17 / 4.9 \%$ & $3 / 2.8 \%$ \\
\hline $\mathrm{N}=376$ & $\mathrm{~N}=279$ & $\mathrm{~N}=97$ \\
\hline $139 / 37 \%$ & $121 / 43.4 \%$ & $18 / 18.6 \%$ \\
\hline $170 / 45.2 \%$ & $134 / 48.0 \%$ & $36 / 37.1 \%$ \\
\hline $67 / 17.8 \%$ & $24 / 8.6 \%$ & $43 / 44.3 \%$ \\
\hline $\mathrm{N}=491$ & $\mathrm{~N}=344$ & $\mathrm{~N}=147$ \\
\hline 225 / 45.8\% & $177 / 51.5 \%$ & $48 / 32.7 \%$ \\
\hline $219 / 44.6 \%$ & $149 / 43.3 \%$ & $70 / 47.6 \%$ \\
\hline 47 / 9.6\% & $18 / 5.2 \%$ & $29 / 19.7 \%$ \\
\hline
\end{tabular}


groups also showed movement toward employment, or a positive alternative such as going to school, with $43.4 \%$ of asylum seekers, $18.6 \%$ of refugees, and $33.1 \%$ of the whole dataset making positive changes. At year two, even larger gains toward employment status were made, $51.5 \%$ for asylum seekers, $32.7 \%$ for refugees, and $41.4 \%$ for the full dataset.

\section{Discussion}

Implications of findings

To our knowledge this is the largest database of torture survivors in one country ever documented in a professional publication. Our information indicates that at least 125 countries are likely to currently practice or have recently practiced torture. Most of these countries are in Africa, followed by Asia. A huge majority $(87 \% / 109)$ of the 125 countries represented in our dataset have signed the UNCAT, agreeing to not torture.

The implications of our study's findings are profound. Despite signing the UNCAT, numerous countries continue to practice torture and other forms of ill-treatment. Although we cannot say this study is a representative sample of the rest of the world, we can say that torture occurred in specific countries that signed the UNCAT. If this type of documentation on torture survivors could be combined with similar information from rehabilitation centers throughout the world, the aggregated information could lend powerful support to efforts to monitor the treatment of detainees, to prevent torture, and to build stronger rehabilitation centers for those who have been tortured.

Our presentation and discussion of this dataset fulfills the four goals of this report. Firstly, the NCTTP dataset fills a void of demographic, diagnostic, and type of torture data from multiple sites across a large country. Our study provides a broad spectrum of demographic and social data and data describing the torture experience.

Over $90 \%$ of individuals for whom we have diagnostic information had diagnoses of PTSD, major depressive disorder (MDD), or PTSD co-morbid with depression, indicating significant psychiatric impairment. The high rate of PTSD following rape found in this study is important clinical information, and this finding needs to be shared with health professionals and policy makers. The very high rates of PTSD and MDD for the torture survivors in our study show the severe repercussions of torture on health and mental health and demonstrate the need for access to effective rehabilitation services. In addition, our research shows that accessing treatment within the first one year of entering the US is associated with a lower rate of major depressive disorder in torture survivors, highlighting the importance of ensuring quick access to services.

The predominant psychiatric diagnoses of PTSD and depression found in our sample seem incomplete given the wider range of psychiatric conditions that many torture survivors experience and report, such as head trauma and periods of unconsciousness. ${ }^{31-32}$ Major neuro-cognitive issues may be greatly under-reported in these data, as well as in other clinical settings. Having just a few individuals report psychotic symptoms in our study seems surprising when compared with other studies that have reported high rates of psychotic symptoms and frank psychosis among those in treatment. ${ }^{33-35}$ Further clarification of how diagnoses are made and reported needs to be considered in future studies.

Most survivors in our sample experienced multiple torture events, and the number of types of torture they experienced pre- 
dicted whether they were diagnosed with PTSD and/or MDD. Future clinical research should collect clients' estimate of the frequency and duration of their torture experiences. Although there are measurement and interpretation challenges associated with efforts to quantify torture, it is clinically very important.

The higher rates of PTSD related to number of types of torture reported by torture survivors speak to the high importance of a thorough and accurate diagnostic interview in which time is allowed to let the torture survivor talk and be heard regarding their experiences of torture. The literature describes the importance of a diagnostic evaluation by physicians and or other licensed professionals who have received special training and who have experience in working with torture survivors. ${ }^{35-37}$

The training is especially important because of the complexities involved in psychiatric assessment of torture survivors, including

1. The likely underreporting of types of torture, especially of a sexual nature, which are usually harder to talk about.

2. Possible challenges of applying the US Diagnostic Statistical Manual (DSM) or another country's accepted professional criteria for psychiatric diagnosis (i.e., are these criteria able to capture the enormous suffering and broad experiences of torture?)

3. The cross cultural challenges in being able to provide accurate, comfortable communication between the torture survivor and the professional provider not just in terms of language, but also in terms of culture, and in terms of acceptance of each other and each other's world view, way of thinking, and way of talking or not talking. ${ }^{22,38,39}$
Accomplishing our second goal, we have established that tortured asylum seekers and refugees receiving services in the US have different diagnostic and social profiles from each other. Our findings should encourage further study of the impacts of immigration status on the repercussions of torture to inform treatment planning. It may be that asylum seekers and refugees have different trajectories and time courses in treatment and recovery, stemming from their different backgrounds in their countries of origin, cultural values, and their torture, migration and resettlement experiences.

By the time they reach the country of resettlement, refugees may have spent years in refugee camps, filled with danger, boredom or both. In our study, asylum seekers were younger and had higher levels of education in their home countries compared to refugees, perhaps denoting a more stable early life for asylum seekers as compared to that of refugees? If, as our study shows, asylum seekers have higher diagnoses of serious mental illness, such as PTSD and MDD, as compared to refugees, at intake, this may be the result of more abrupt and violent torture, higher uncertainties in fleeing from severely dangerous situations, and high unpredictability in their migration to and resettlement experience in the US.

Asylum seekers receive no financial support from the US government. They have to find a place to live, food, clothing and legal assistance for their asylum claim without government assistance.

Asylum seekers may have to stay in the US for years awaiting a decision on their asylum claim. In their 2013 study, Raghavan et al found the largest predictor of improvement in symptoms was gaining secure immigration status. ${ }^{40}$

Refugees in the US do receive financial, 
medical, and other support from the federal government for at least eight months after entering the country. The fact that the Muslim religion, which many refugees practice, prohibits alcohol may also be helpful, as there is a low prevalence of substance abuse and its associated problems.

There has been a great deal written about the chronic course of refugees following severe trauma, torture, and displacement from their homelands. ${ }^{41}$ Less information appears to be available in the literature on the recovery course of asylum seekers. We understand that there are individual and group differences, and furthermore the resettlement experience for each of these two groups varies considerably across the world.

Of course, those under 18 in either group, whether resettling in the US or elsewhere, may have had disrupted educational opportunities due to war and other circumstances, and adults may have had limited occupational opportunities.

Rather than being applied directly to a specific refugee or asylum seeker, the type of contextual information described above can be used as a way of understanding the slower progress of some refugees, perhaps especially those who are older, and in understanding the perhaps greater number of symptoms of some asylum seekers. Taking into account this type of information can also help the provider be more comfortable and have more confidence in assessing torture survivors.

For the third goal of our paper, our pilot findings of improvement in immigration and employment status following one and two years of receiving services from NCTTP centers provide a starting point to track meaningful areas of potential change for torture survivors receiving treatment in our centers. Our experience also demonstrates that it is feasible to collect functional data over time from torture survivors to docu- ment progress. Although the sample size was small for the follow up groups, the data does give us some indication of what may occur in the lives of torture survivors two years into treatment and provides information useful in guiding services and policy efforts.

Thirty-six and $49 \%$ of the torture survivors in our study made progress in their immigration status at follow up in one and two years, respectively, after intake (see Table 6). These percentages of improvement may be lower than ideal. However, to fully understand and appreciate these results, it is necessary to take note of extenuating information related to the immigration barriers experienced in the US for the asylum seekers and refugees in our study.

For both asylum seekers and refugees in our country, immigration status progresses in a step by step fashion. After achieving one step in the immigration process, there are specific waiting periods required by the US government before an individual can make an application for the next step. Application forms at each step are complicated, require a good command of English, and administrative fees and are somewhat costly for those in lower socio-economic classes. The application process can be challenging, especially for older refugees who may have trouble learning English and in filling out the application, and who also may not have the money to pay administrative fees.

Asylum seekers come into the US and have one year in which to make a formal asylum application. Application for asylum involves hiring and paying an immigration attorney or a similar alternative to help guide and represent the person through the complicated US immigration system. The time it takes from formally applying for and receiving asylum varies a great deal, depending on the city of residence and jurisdiction for asylum cases to be heard, with correspon- 
ding differences in average length of time for asylum cases to be adjudicated. ${ }^{42}$

Administrative and other delays are very common as most asylum seekers wait many years before receiving asylum. Some are never granted asylum, spend time in detention facilities, and are deported from the US. As asylum seekers receive no financial support from the US government, it can be very challenging, both physically and emotionally, for people to support themselves and pay legal fees during the often prolonged, uncertain wait to be granted asylum. Asylum seekers can apply for a work permit after they have formally applied for asylum.

In addition to the physical and emotional hardships of the wait for asylum, asylum seekers also must undergo sometimes very emotional, strict questioning about their backgrounds and motives for coming to the US. Clients of NCTTP centers in our study often received at least some partial help toward their immigration challenge, in terms of discounted or free legal help, social service support, medical insurance, or discounted or free medical treatment.

Both refugees and asylum seekers showed improvements in employment over the two-year period for which we have data. Similar to our explanation of improvements in immigration status, it is very important to look at the results while keeping in mind the extenuating circumstances for the refugees and asylum seekers. While refugees showed a higher employment rate than asylum seekers at intake, asylum seekers at follow up showed a higher employment rate than refugees.

With their higher education, relative youth, and perhaps shorter overall migration journey from fleeing their country of torture to achieving requirements for asylum, the asylum seeker may show a faster rate of recovery in comparison to a refugee. Of course, there are many individual differences.

The higher age and overall lower educational level of many refugees, compared to asylum seekers, may make it harder for refugees, especially the older adults to learn new language and new skills required for many employment situations.

Given our study design of a retrospective chart review, we are not able to attribute the changes we observed in functional outcomes to a specific intervention by NCTTP programs. Many factors likely affected the positive changes in immigration status and employment at one and two-year follow up, such as the length of time in the US prior to treatment engagement. Employment status has a more variable course than immigration status, i.e., individuals can obtain and lose employment for many reasons. Consequently, employment status over time is more challenging to accurately collect because it changes more frequently. The US experienced a significant economic downturn in 2008, the year we began our study, and the economic recovery situation during the six years of this study likely affected the lives of refugees and of asylum seekers, and also may have delayed potential improvements for these two groups in both immigration and employment status.

\section{Difficult decisions and challenges}

Some of the difficult decisions and challenges we faced may be unique to the US, such as the manner in which we need to protect the privacy of each research subject. Also, the two main groups of survivors treated by NCTTP centers, refugees and asylum seekers, may not be reflective of survivors served in other parts of the world.

In this paper, we included a description of our IRB process and an examination and comparison of the characteristics and 
experiences of refugees and asylum seekers because: a) we feel that this information is very important to clinicians in the US who work with these two groups, and b) it is useful for all clinicians regardless of location to understand some of the challenges faced by clinicians in other parts of the world. It is this type of communication and sharing which can increase our understanding of the experiences of torture survivors and enhances opportunities for collaboration across cultural and professional boundaries.

To fulfill our important fourth goal of sharing information with torture treatment organizations in other regions of the world that might wish to build their own database and join us in these research endeavors, we have described in some detail in the Methods section the various aspects of the process in which the NCTTP and its R\&D Committee engaged to produce a large database on torture survivors receiving treatment in the US. As we stated earlier, no group of centers in one large country or region of the world can effectively or comprehensively represent or report on torture that has occurred across the world. However, by working together we have a good chance of succeeding.

\section{Success of the project}

The success of the NCTTP Data Project can be attributed to the "buy in" all 23 centers had with its collaborative nature. Throughout the project, the group of participating centers made decisions together related to the IRB protocol, what variables to collect, and how and where the reports on the data would be submitted for publication.

\section{Limitations}

To be clear, this is not a representative sample. This study represents torture survivors who have sought treatment in NCTTP torture treatment programs in the
US over a six-year period. Thus, those who have not sought treatment, sought treatment outside of the time period of this study, or who have been treated in other types of programs in the US or in other countries were not included. This limits the representativeness for other torture survivors residing in the US or in other countries. In addition, data on torture experiences was gathered through self-report, and we did not obtain independent confirmation.

It is important to note that the data we collected is generally representative of the larger treatment centers within the NCTTP. Thirteen of the original 23 NCTTP centers have maintained involvement in the data project for at least five of the last six years of the project, until the end of FY2013. Several of these are larger clinical centers, which serve a majority of the NCTTP clients. For centers that have not maintained participation in the project, funding appears to have been a key factor.

Because of shifting funding and staffing patterns across the centers, not all NCTTP centers provided complete demographic data on their clients, and therefore the amount of missing data for some variables differs across years and across centers, depending upon what data each center submitted. Also, the number of data variables collected was expanded each year. Both of these factors contribute to the project's varying Ns for different variables. Not all centers were able to participate in collecting outcome data for immigration or employment due to a lack of resources. This limited the size of our sample on which we have follow up data.

Both a limitation and strength of this project is the chart review IRB approval we obtained. In this study, we were restricted to collecting data that had already been collected for other purposes, such as for clinical treatment or for reporting to a 
funder. We were not able to administer standardized scales or surveys or to plan or administer interventions in a prospective manner, thus limiting the scope of what we could study. The strength of this method of research is that it is easier to carry out and easier to obtain and maintain IRB approval. It enabled us to build a foundation and track record of successful collaboration across the NCTTP from which to launch more stringent outcome research in the future.

\section{Future research directions}

Studies are needed to document the types, duration, and effectiveness of treatment. The diverse centers that participated in our study reported a variety of approaches to treatment, and it would be useful to compare these different approaches in future studies.

Many studies in the literature have indicated that traumatized refugees have long-term problems and psychiatric morbidity, but the contributing factors and mechanisms for this are not well understood. ${ }^{41}$ The NCTTP's large and diverse torture survivor sample provides a useful opportunity to examine these issues. For example, perhaps measuring progress toward the usually long-term goal of US citizenship are more realistic and better suited for a longitudinal study over more than two years.

Following the trend in the professional literature, in FY2014 the NCTTP began to collect data on the prevalence of hypertension, diabetes, traumatic brain injuries, and cardiovascular problems in the torture survivors we serve. The NCTTP future research plans include conducting treatment outcomes research on changes in quality of life and functioning.

In addition, plans include more thoroughly measuring disabling psychiatric conditions, such as traumatic brain injuries and dementia, and physical health conditi- ons, such as hypertension, diabetes, and cardiovascular illness. ${ }^{26-28,43}$

\section{Conclusion}

This report demonstrates the feasibility of a large research project across torture treatment centers in the US and provides a large dataset of demographic, diagnostic and type of torture data on torture survivors in treatment from 125 countries. The value of a very large database on torture survivors offers researchers the tools to assess patterns and associations of immigration status, torture experiences, and resulting diagnoses.

Risk factors for PTSD and other syndromes are more likely to be detected, if they exist, with the statistical power the large database provides. High-risk factors for PTSD and MDD in torture survivors appear to be reporting more than three types of torture, reporting rape, and asylum seeker immigration status. This large study raises several questions: Are diagnoses in torture survivors being missed? What are the long-term social and medical outcomes of torture? What is the effectiveness of the treatment provided toward addressing the long-term repercussions of torture? Further research is needed to answer these issues.

As long as torture persists around the world, survivors with critical need for treatment will remain. Resources for prevention, treatment, and research of torture survivors need to be strengthened. To have a significant impact, clinicians and researchers should work together across continents to describe the profile of torture survivors seeking rehabilitation across the world and determine effective intervention approaches.

\section{Acknowledgements}

Member Centers of the National Consortium of Torture Treatment Programs that sub- 
mitted client-level data during FY2008 -

2013 (Oct 1, 2007 to Sept 30, 2013):

- Access Center for Survivors of Torture, Dearborn, MI

- Advocates for Survivors of Torture and Trauma, Baltimore, MD (center closed 2015)

- Bellevue/NYU Program for Survivors of Torture, New York, NY

- Boston Center for Refugee Health and Human Rights, Boston, MA

- Center for Survivors of Torture, Austin \& Dallas, TX

- Center for Survivors of Torture, AACI, San Jose, CA

- Center for Survivors of Torture and War Trauma, St. Louis, MO

- Center for Victims of Torture, Minneapolis, $\mathrm{MN}$

- Florida Center for Survivors of Torture, Clearwater \& Miami Springs, FL

- Heartland Alliance Marjorie Kovler Center, Chicago, IL

- Harvard Program for Refugee Trauma, Cambridge, MA

- International Institute of New Jersey, Jersey City, NJ - Cross-Cultural Counseling Center (center closed 2012)

- Khmer Health Advocates, W. Hartford, CT

- Liberty Center, Philadelphia, PA (center closed in 2010)

- Lowell Community Health Center, Lowell, MA

- Program for Survivors of Torture and Severe Trauma at NVFS, Falls Church, VA

- Program for Torture Victims, Los Angeles, CA

- Rocky Mountain Survivors Center, Denver, CO (center closed in 2010)

- Survivors International, San Francisco, CA

- Survivors of Torture International, San Diego, CA
- Torture Abolition and Survivors Support Coalition, Washington, DC

- Torture Treatment Center of Oregon, OHSU, Portland, OR

- Utah Health and Human Rights Project, Salt Lake City, UT

We would also like to acknowledge the contributions of the Legal Aid Foundation of Los Angeles; Libertas Center for Human Rights at Elmhurst Hospital, Elmhurst, New York; Survivors International, UCSF Trauma Recovery Center, San Francisco, CA; International Counseling \& Community Services, Lutheran Community Services, Seattle, WA; International Institute of Connecticut, Bridgeport, CT, and the Nationalities Service Center, Philadelphia, PA.

Oregon Health \& Science University's Institutional Review Board (IRB\# 4290).

The Jacob \& Valeria Langeloth Foundation, 2004 grant to the Torture Treatment Center of Oregon at OHSU provided important partial funding to initiate this project.

The NCTTP's Research \& Data Subcommittee.

Crystal Riley, MA, Oregon Health \& Science University, is the corresponding author for this manuscript. 


\section{References}

1. "60 Million People Fleeing Chaotic Lands, U.N. Says", The New York Times. 2015 Jun 18;A1.

2. Modvig J, Jaranson J. A global perspective of torture, political violence, and health. In: Wilson JP, Drozdek B, eds. Broken Spirits: The Treatment of Traumatized Asylum Seekers, Refugees, War and Torture Victims. New York, NY, BrunnerRoutledge Press, 2004; 33-52.

3. Kinzie JD, Goetz RR. (1996). A century of controversy surrounding posttraumatic stress spectrum syndromes: The impact on DSM-III and DSM-IV. J Trauma Stress. Wiley-Blackwell; 1996 Apr;9(2):159-79.

4. Jaranson JM, Quiroga J. Evaluating the services of torture rehabilitation programmes: History and recommendations. Torture. 2011;21(2):98140.

5. IRCT. History of the IRCT [Internet]. [cited 2015 Jan 7]. Available from: http://www.irct.org/ about-us/what-is-the-irct/history.aspx

6. Reiter RB, Zunzunegui MV, Quiroga J. Guidelines for Field Reporting of Basic Human Rights Violations. Human Rights Quarterly. JSTOR; 1986 Nov;8(4):628-33.

7. Kinzie, JD, Tran, KA, Breckenridge, A, and Bloom, JD. An Indochinese refugee psychiatric clinic: culturally accepted treatment approaches Am J Psychiatry. American Psychiatric Publishing; 1980 Nov;137(11):1429-32.

8. Mollica R, Wyshak G, Lavelle J. The psychosocial impact of war trauma and torture on Southeast Asian refugees. Am J Psychiatry. American Psychiatric Publishing; 1987 Dec;144(12):1567-72.

9. Westermeyer J. Prevention of mental disorder among Hmong refugees in the U.S.: Lessons from the period $1976-1986$. Social Science \& Medicine. Elsevier BV; 1987 Jan;25(8):941-7.

10. Quiroga J, Jaranson JM. Politically-motivated torture and its survivors: A desk study review of the literature. Torture (Thematic Issue). 2005;15(23): $1-111$.

11. Torture Victims Relief Act 1998, P.L. 105-320, 18 U.S.C. \$ 2340(1).

12. Kjersem HJ. Migration medicine in Denmark: evaluation of a number of migration medicine problems among asylum seekers and refugees. Copenhagen, Denmark, Danish Red Cross; 1996.

13. Jaranson JM, Butcher J, Halcon L, Johnson DR, Robertson C, Savik K, et al. Somali and Oromo Refugees: Correlates of Torture and Trauma History. Am J Public Health. American Public Health Association; 2004 Apr;94(4):591-8.

14. Wenzel T, Kastrup MC, Eisenman DP. Survivors of Torture: A Hidden Population. Immigrant Medicine. Elsevier BV; 2004. p. 653-63.
15. Masmas TN, Moller E, Buhmannr C, et al. Asylum seekers in Denmark - a study of health status and grade of traumatization of newly arrived asylum seekers. Torture. 2008; 18(2):77-86.

16. Steel Z, Chey T, Silove D, Marnane C, Bryant RA, van Ommeren M. Association of Torture and Other Potentially Traumatic Events With Mental Health Outcomes Among Populations Exposed to Mass Conflict and Displacement. JAMA. American Medical Association (AMA); 2009 Aug 5;302(5):537-49.

17. United States Office of Refugee Resettlement [Internet]. [cited 2015 Jul 3]. Available from: http://www.acf.hhs.gov/programs/orr/about/history

18. Martin DC, Yankay JE, Annual Flow Report Refugees and Asylees: 2013. U.S. Department of Homeland Security, Office of Immigration Statistics Policy Directorate, DHS Office of Immigration Statistics.

19. Eisenman DP, Keller AS, Kim G. Survivors of torture in a general medical setting: how often have patients been tortured, and how often is it missed? Western Journal of Medicine. BMJ; 2000 May 1;172(5):301-4.

20. Crosby SS, Norredam M, Paasche-Orlow MK, Piwowarczyk L, Heeren T, Grodin MA. Prevalence of torture survivors among foreign-born patients presenting to an urban ambulatory care practice. J Gen Intern Med. Springer Science \& Business Media; 2006 Jul;21(7):764-8.

21. Willard CL, Robin M, Lawless M. The Prevalence of Torture and Associated Symptoms in United States Iraqi Refugees. J Immigr Minor Health. Springer Science \& Business Media; 2013 Apr 6;16(6):1069-76.

22. Başoğlu M, Livanou M, Crnobarić C. Torture vs Other Cruel, Inhuman, and Degrading Treatment. Archives of General Psychiatry. American Medical Association (AMA); 2007 Mar 1;64(3):277.

23. Krammer S, Kleim B, Simmen-Janevska K, Maercker A. Childhood Trauma and Complex Posttraumatic Stress Disorder Symptoms in Older Adults: A Study of Direct Effects and SocialInterpersonal Factors as Potential Mediators. J Trauma Dissociation. Informa UK; 2015 May 26;1-16.

24. Sumner JA, Kubzansky LD, Elkind MSV, Roberts AL, Agnew-Blais J, Chen Q, et al. Trauma Exposure and Posttraumatic Stress Disorder Symptoms Predict Onset of Cardiovascular Events in Women Clinical Perspective. Circulation. Ovid Technologies (Wolters Kluwer Health); 2015 Jun 29;132(4):251-9.

25. Kinzie JD, Riley C, McFarland B, Hayes M, 
Boehnlein J, Leung P, et al. High Prevalence Rates of Diabetes and Hypertension Among Refugee Psychiatric Patients. J Nerv Ment Dis. Ovid Technologies (Wolters Kluwer Health); 2008;196(2):108-12.

26. Agyemang C, Goosen S, Anujuo K, Ogedegbe G. Relationship between post-traumatic stress disorder and diabetes among 105180 asylum seekers in the Netherlands. Eur J Public Health. Oxford University Press (OUP); 2011 Sep 27;22(5):65862.

27. Wagner J, Berthold SM, Buckley T, Kong S, Kuoch T, Scully M. Diabetes Among Refugee Populations: What Newly Arriving Refugees Can Learn From Resettled Cambodians. Current Diabetes Reports. Springer Science \& Business Media; 2015 Jul 5;15(8).

28. Marshall GN, Schell TL, Wong EC, Berthold SM, Hambarsoomian K, Elliott MN, et al. Diabetes and Cardiovascular Disease Risk in Cambodian Refugees. Journal of Immigrant and Minority Health. Springer Science \& Business Media; 2015 Feb 5;

29. Mollica RF, Chernoff MC, Megan Berthold S, Lavelle J, Lyoo IK, Renshaw P. The mental health sequelae of traumatic head injury in South Vietnamese ex-political detainees who survived torture. Comprehensive Psychiatry. Elsevier BV; 2014 Oct;55(7):1626-38.

30. National Consortium of Torture Treatment Programs. [cited 2015 Jun 15]. Available from: http://www.ncttp.org/research.html

31. Keatley E, Ashman T, Im B, Rasmussen A. Self-Reported Head Injury Among Refugee Survivors of Torture. J Head Trauma Rehabil. Ovid Technologies (Wolters Kluwer Health); 2013;28(6):E8-13.

32. Mollica RF, Lyoo IK, Chernoff MC, Bui HX, Lavelle J, Yoon SJ, et al. Brain Structural Abnormalities and Mental Health Sequelae in South Vietnamese Ex-Political Detainees Who Survived Traumatic Head Injury and Torture. Archives of General Psychiatry. American Medical Association (AMA); 2009 Nov 1;66(11):1221.

33. Kinzie, JD, Boehnlein, JK. Post-traumatic Psychosis among Cambodian refugees. J Trauma Stress. Wiley-Blackwell; 1989 Apr;2(2):185-98.

34. Norredam M, Jensen M, Eketran M. Psychotic symptoms in refugees diagnosed with PTSD: A series of case reports. Nord J Psychiatry. Informa UK; 2011 Sep;65(4):283-8.

35. Kinzie, JD. Guidelines for psychiatric care of torture survivors. Torture 2011;21(1):18-26.

36. Kinzie JD, Jaranson JM, Kroupin GV. Diagnosis and Treatment of Mental Illness. Immigrant Medicine. Elsevier BV; 2004. p. 639-51.
37. Kinzie JD, Evaluation and Psychotherapy of Indochinese Refugee Patients. Am J Psychother. 1981 Apr;35(2):251-261.

38. Boehnlein JK, Kinzie JD. Refugee Trauma. Transcultural Psychiatric Research Review. 1995;32:223-252.

39. Kinzie JD. Cross-cultural Treatment of PTSD, In: Core Approaches for the Treatment of PTSD. Wilson J, Friedman M, Lindy J, editors. Guilford Press; 2001.

40. Raghavan S, Rasmussen A, Rosenfeld B, Keller AS. Correlates of symptom reduction in treatment-seeking survivors of torture. Psychological Trauma: Theory, Research, Practice, and Policy, 2013 Jul;5(4):377-83.

41. Marshall GN, Schell TL, Elliott MN, Berthold S, Chun C. Mental health of Cambodian refugees two decades after resettlement in the United States. JAMA. American Medical Association (AMA); 2005 Aug 3;294(5):571.

42. Immigration Court Backlog Tool: Pending Cases and Length of Wait in Immigration Courts [Internet]. [cited 2015 July 8]. Available from: http://trac.syr.edu/phptools/immigration/court backlog

43. Berthold SM, Kong S, Mollica RF, Kuoch T, Scully M, Franke T. Comorbid Mental and Physical Health and Health Access in Cambodian Refugees in the US. J Community Health. Springer Science \& Business Media; 2014 Mar 21;39(6):1045-52. 